\title{
New Models for Estimation of Solar Radiation for Five Cities of Pakistan
}

\author{
Atteeq $\operatorname{Razzak}^{1}$, Zaheer Uddin ${ }^{2}$, M. Jawed Iqbal ${ }^{3}$ \\ ${ }^{1}$ Department of Mathematics, University of Karachi, Pakistan,atteeq.razzak@uok.edu.pk, \\ ${ }^{2}$ Department of Physics, University of Karachi, Pakistan, zuddin@uok.edu.pk \\ ${ }^{3}$ Institute of Space Science \& Technology, University of Karachi, Pakistan, javiqbal@uok.edu.pk
}

\begin{abstract}
The increasing demand for electricity due to the ordinary person's lifestyle has put immense pressure on fossil fuels. The rapid depletion of fossil fuels has made scientists and engineers search and adopt alternative sources of energy. Renewable energies, e.g., wind, hydro, biogas, solar, etc., are an excellent alternative to conventional energy sources. In this paper, we developed three models for direct beam solar radiation (BSR), diffuse solar radiation (DSR), and global solar radiation (GSR) for five cities (Karachi, Hyderabad, Lahore, Quetta, and Peshawar) of Pakistan. In these models, BSR, DSR, and GSR are given as a function of day-number. Three types of solar radiations have been calculated through the models developed in this study. The results are compared with the corresponding values calculated by the standard clear sky ASHRAE model. A good agreement is found between these values. For validation of results, Root means square error (RMSE), Mean Absolute error (MABE), Mean Absolute percent error (MAPE), and chi-square $\left(\chi^{2}\right)$, and coefficient of determination are calculated and found to be in the accepted range. It has also been found that DSR, BSR, and GSR have an inverse relation with Latitude.
\end{abstract}

Key words : ASHRAE Model, Beam, and Direct solar radiation, Modelling, Global, Solar,Solar radiations,

\section{INTRODUCTION}

Most countries in the world have already adopted renewable energy for the generation of electricity. Specially in this pandemic era when scientists are confined to their labs and free moment is prohibited and due to COVID-19 mathematical and physical analysis of renewable energy is more preferred than going out for free research. [1].Countries in South Asia have still not fully exploited the vast potential of renewable energy in this region. Proper research and adoption of renewable energy is the need of the people of Pakistan. Compared to many countries in the world, especially Europe, Pakistan has many solar potentials. Proper research and adoption of solar energy are still pending in Pakistan. The main idea of the manuscript resembles the work carried out by [2] but let us first see the relation between solar radiation and other climatic factors and weather intuitively.

Solar radiations penetrating the atmosphere and striking earth can be grouped into two, i.e., radiations that hit land in straight-line joining earth and sun and the other that is mostly dispersed and propagate through aerosols present in the air, namely beam radiations and diffuse radiations, respectively. To find global radiations, the sum of the beam and diffuse radiations are commonly used. If the number of diffuse traditions will be equal to or less than $25 \%$ of global radiations, the sky would be considered explicit. To design solar energy systems or devices, monthly mean daily global data or solar radiation is used. Still, hourly solar radiation data gives far better performance and precise information about solar energy systems on horizontal surfaces. These hourly radiation data is helpful to engineers in designing solar devices for obtaining maximum output. In India, most sites receive an excessive amount of solar radiation energy that can be harvested by setting up solar energy technology there. Indian Meteorological Department (IMD) has implanted respective technology at these sites and measured sunshine duration, global radiations, and diffuse radiation data that gives a monthly average of hourly global and diffuse radiations used in this study.[3]

Secondly, the weather condition plays a vital role in the lives of people and their environment. And so, its study has a notable significance [4].To monitor and forecast the climatic phenomenon, position and solar radiation are the two significant parameters which undoubtedly play a vital role.[5] .The exact information about the accessibility of universal solar radiation is therefore required to design and optimize solar energy conversion systems.[6][7]. Consequently, the absolute solar energy potential is also of great significance to examine whether the 
solar energy equipment and its components are effectively working or not [5][8]. Another significant factor/parameter to study the climatic phenomenon is temperature- "A physical quantity that shows the intensity of heat of a matter." It has a considerable impact on many climatic elements, including humidity, precipitation, dew point temperature, and atmospheric pressure.[9]

In terms of temperature changes, the impact of changes in average temperature values is trivialized by the changes in extreme values of temperature. The variation in the climate is also significant as it clarifies the human perception of weather.[10] . In addition, the relative humidity and dew point temperature are also important parameters as these factors are used to measure atmospheric moisture.[11] . The relative humidity can be influenced by solar radiation, dew point temperature, and ambient temperature. [12]. However, the relative humidity itself significantly impacts determining "How effectively metals, electrical devices, and biological stuff are physically performing?" [13] . The relative humidity is measured as a percentagemore than $80 \%$ causes discomfort, whereas $100 \%$ humidity means the air-water mixture is more humid.[14]

On the other hand, scientists consider that dew point is the best way to measure human comfort. It can be stated as the temperature when the rate of condensation becomes equal to the speed of evaporation. Thus, it can also be said that the dew point temperature is the temperature at which the partial vapor pressure becomes comparable to that of partial saturation vapor pressure. [15]

Dew point is, therefore, a valuable and effective parameter to forecast rain, fog, and frost. It can also be used to forecast the chances of a thunderstorm; for instance, the temperature higher than $60^{\circ} \mathrm{C}$ at lower temperature forecasts intense thunderstorms. [4] . Meteorologists have been studying the trends of solar radiation and other parameters on a global scale, although it may overshadow the substantial temporal and spatial climate variations. [16] . The groundbased meteorological station is the genuine place to collect, organize, and generate climatic data and conduct climatic research. In 2013, the research was conducted to study the daily and monthly changes in solar radiation, relative humidity, air temperature, and dew point. The relevant data were collected from one of the meteorological stations in Damak, Nepal.

The daily analysis of climatic change shows that air temperature follows the sine function, though solar radiation and relative humidity satisfy the Gaussian function. These two parameters exhibit an increasing and a decreasing trend, respectively. On the contrary, the research claims that the fourth parameter, "dew point, "indicates complex behavior.

On the other hand, the following observations were made based on a monthly analysis of climatic change.

- Solar radiation, dew point, and air temperature follow the same pattern, which decreases in winter and increases in summer.

- The study relating to the relative humidity shows that April is the non-humid month of the year.

- The study relating to the temperature shows that the temperature usually decreases in summer than in winters. [17]

Above mentioned factor, though, impacts solar radiation, but the fundamental element that can be very important while observing and estimating solar radiation is the sun's positioning. This article mainly deals with the relation of solar radiations (DSR,BSR, and GSR) and Latitude.

\section{METHODOLOGY}

Mathematical models have been developed for direct beam solar radiation, diffuse solar radiation, and global solar radiation for five cities of Pakistan. A quadratic equation as a function of day-number $(n)$ is developed to estimate direct beam solar radiation and diffused solar radiation. The model is given below. We have taken the motivation of our work from the ASHRAE model of estimating solar radiation; equations (4-6) describe them.

$$
\begin{aligned}
& I_{B S R}=a_{o}+a_{1} n+a_{2} n^{2} \#(1) \\
& I_{D S R}=b_{o}+b_{1} n+b_{2} n^{2} \#(2)
\end{aligned}
$$

The following model is developed for the Estimation of global solar radiation.

$$
\ln \left(I_{G S R}\right)=c_{o}+c_{1} n^{3}+c_{2} n^{5} \#(3)
$$

Regression and curve fitting methods have been used to find the model's coefficients (a's, b's, and c's). To compare the results, all three radiations are calculated by standard clear sky ASHRAE model using the following equations.[18]. Values of ASHRAE constants are given (see Appendix A)

$$
\begin{gathered}
I_{G S R}=I_{B S R} \cos \theta_{z}+I_{D S R} \#(4) \\
I_{B S R}=A e^{\left(-B / \cos \theta_{z}\right)} \#(5) \\
I_{D S R}=C I_{B S R} \#(6)
\end{gathered}
$$


$\boldsymbol{I}_{G S R}$ representglobal solar radiation (GSR), $\boldsymbol{I}_{\boldsymbol{B S R}}$ is direct beam solar radiation (BSR), and $\boldsymbol{I}_{\boldsymbol{D S R}}$ is direct beam solar radiation (DSR, for this paper, we developed three models for global solar radiate on (GSR) direct beam solar radiation (BSR), direct beam solar radiation (BSR), (DSR) for five cities (Karachi, Hyderabad, Lahore, Quetta, and Peshawar) of Pakistan. In these models, BSR, DSR, and GSR are given as a function of day-number. Three types of solar radiations have been calculated through the models developed in this study. The results are

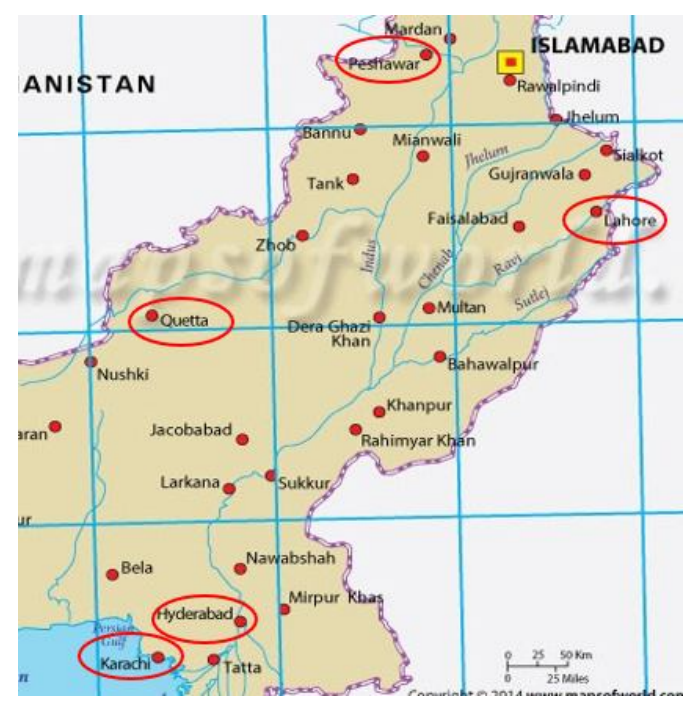

Figure 1 Longitudinal and Latitudinal Map of Pakistan Courtesy www.mapsoftword.com

\section{RESULTS AND DISCUSSION}

Direct beam, diffuse, and global solar radiations have been calculated for each day of the year at noon

Direct beam solar radiation (BSR)

\begin{tabular}{|c|c|c|}
\hline Karachi & $\ln \left(\mathrm{I}_{\mathrm{BSR}}\right)=6.553994+0.005545 \mathrm{n}-1.6 \mathrm{E}-5 \mathrm{n}^{2}$ & (7) \\
\hline Hyderabad & $\ln \left(\mathrm{I}_{\mathrm{BSR}}\right)=6.529075+0.005827 \mathrm{n}-1.7 \mathrm{E}-5 \mathrm{n}^{2}$ & (8) \\
\hline Lahore & $\ln \left(\mathrm{I}_{\mathrm{BSR}}\right)=6.376428+0.007413 \mathrm{n}-2.1 \mathrm{E}-5 \mathrm{n}^{2}$ & (9) \\
\hline Quetta & $\ln \left(\mathrm{I}_{\mathrm{BSR}}\right)=6.411+0.00702 \mathrm{n}-2 \mathrm{E}-5 \mathrm{n}^{2}$ & (10) \\
\hline Peshawar & $\ln \left(\mathrm{I}_{\mathrm{BSR}}\right)=6.297143+0.008501 \mathrm{n}-2.4 \mathrm{E}-5 \mathrm{n}^{2}$ & (11) \\
\hline \multicolumn{3}{|c|}{ Diffuse solar radiation (DSR) } \\
\hline Karachi & $\mathrm{I}_{\mathrm{DSR}}=56.62688+0.05125 \mathrm{n}-0.000149 \mathrm{n}^{2}$ & (12) \\
\hline Hyderabad & $\mathrm{I}_{\mathrm{DSR}}=56.37212+0.05420 \mathrm{n}-0.000157 \mathrm{n}^{2}$ & (13) \\
\hline Lahore & $\mathrm{I}_{\mathrm{DSR}}=54.73500+0.07209 \mathrm{n}-0.000207 \mathrm{n}^{2}$ & (14) \\
\hline Quetta & $\mathrm{I}_{\mathrm{DSR}}=55.10709+0.06785 \mathrm{n}-0.000196 \mathrm{n}^{2}$ & (15) \\
\hline Peshawar & $\mathrm{I}_{\mathrm{DSR}}=53.82758+0.08189 \mathrm{n}-0.000236 \mathrm{n}^{2}$ & (16) \\
\hline \multicolumn{3}{|c|}{ Global solar radiation (GSR) } \\
\hline Karachi & $\mathrm{I}_{\mathrm{GSR}}=996.02211+0.70461 \mathrm{n}-9.44514 \mathrm{E}-06 \mathrm{n}^{3}+2.955522 \mathrm{E}-11 \mathrm{n}^{5}$ & (17) \\
\hline Hyderabad & $I_{G S R}=991.68788+0.74573 n-9.97283 E-06 n^{3}+3.121382 E-11 n^{5}$ & (18) \\
\hline Lahore & $\mathrm{I}_{\mathrm{GSR}}=963.92937+0.99199 n-1.31172 \mathrm{E}-05 \mathrm{n}^{3}+4.09020 \mathrm{E}-11 n^{5}$ & (19) \\
\hline Quetta & $\mathrm{I}_{\mathrm{GSR}}=969.94067+0.93800 \mathrm{n}-1.25950 \mathrm{E}-05 \mathrm{n}^{3}+3.97395 \mathrm{E}-11 \mathrm{n}^{5}$ & (20) \\
\hline Peshawar & $\mathrm{I}_{\mathrm{GSR}}=948.40317+1.12818 \mathrm{n}-1.49922 \mathrm{E}-05 \mathrm{n}^{3}+4.690313 \mathrm{E}-11 \mathrm{n}^{5}$ & (21) \\
\hline
\end{tabular}

by the standard clear sky ASHRAE model.

\section{STUDY AREA}

For this study, five of the largest cities of Pakistan, namely Karachi $(24.860$, 66.991), Hyderabad (25.96,68.35),Lahore(31.5204,77.33E),Peshawar(34. 0151,71.560E), andQuetta(30.1798,66.997) havebeen considered, except Hyderabad each city is a state capital. Study areas have been highlighted in Figure 1.

through models given in equations (1-3). The log of BSR isa quadratic function of day-number(n), equation (7-11) gives mathematical expression of BSR as a function of ' $n$ ' for Karachi, Hyderabad, Lahore, Quetta, and Peshawar, respectively. The coefficient $a_{o}$ gives the intensity of BSR, in these equations $a_{o}$ has a maximum that occurs for Karachi. Overall, Karachi has more BSR than any other city; Hyderabad has compatible solar power in terms of $\mathrm{BSR}$; the reason is apparent, Karachi $\left(67.13^{\circ}, 24.86^{\circ}\right)$ Hyderabad $\left(68.36^{\circ}, 25.96^{\circ}\right)$ have closer Latitude and longitude values. The maximum values of BSR for all cities occur in the middle of the year (182-184 days of the year). There is not much difference between the maximum value of BSR for each city. According to the values of $a_{o}$ The cities' rank-wise position is as Karachi, Hyderabad, Quetta, Lahore, and Peshawar. This is clear from fig. 1. shows that the top curve represents Karachi (having more BSR available), and the bottom curve represents Peshawar, which has the lowest values of BSR. 


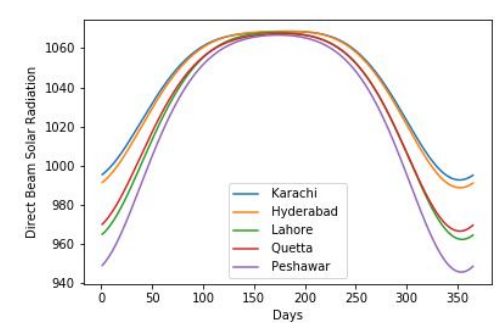

(a)

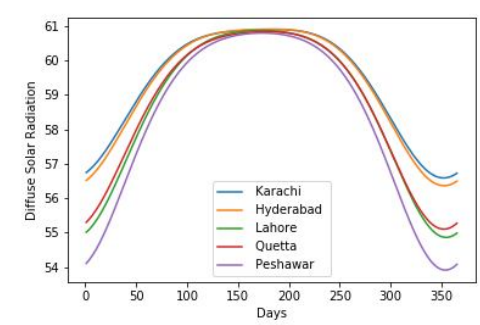

(b)

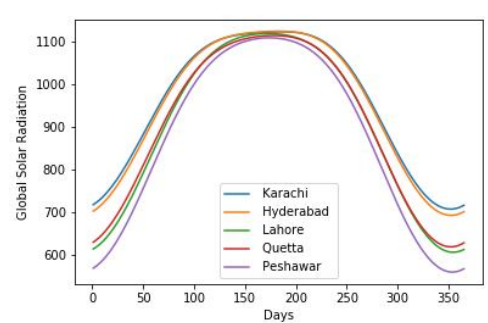

(c)

Figure2. Direct beam, diffused, and global solar radiations for Karachi, Hyderabad, Lahore, Quetta, and Peshawar

Table I: Statistical errors indirect beam, diffused, and global solar radiation for five cities.

\begin{tabular}{|c|l|r|r|r|r|r|}
\hline Solar Radiations & Cities & RMSE & Chi-Square & MABE & MAPE & $\mathrm{R}^{2}$ \\
\hline \multirow{4}{*}{$\begin{array}{c}\text { Direct Beam Solar } \\
\text { Radiations }\end{array}$} & Karachi & 3.721 & 0.013 & 3.311 & 0.318 & 0.981 \\
\cline { 2 - 7 } & Hyderabad & 3.773 & 0.014 & 3.356 & 0.323 & 0.982 \\
\cline { 2 - 7 } & Lahore & 4.298 & 0.018 & 3.821 & 0.372 & 0.987 \\
\cline { 2 - 7 } & Quetta & 4.325 & 0.018 & 3.822 & 0.372 & 0.985 \\
\cline { 2 - 7 } & Peshawar & 4.824 & 0.023 & 4.276 & 0.419 & 0.987 \\
\hline \multirow{4}{*}{$\begin{array}{c}\text { Diffused Solar } \\
\text { Radiations }\end{array}$} & Karachi & 0.242 & 0.001 & 0.180 & 0.306 & 0.975 \\
\cline { 2 - 7 } & Hyderabad & 0.249 & 0.001 & 0.182 & 0.312 & 0.976 \\
\cline { 2 - 7 } & Lahore & 0.293 & 0.002 & 0.207 & 0.361 & 0.981 \\
\cline { 2 - 7 } & Quetta & 0.302 & 0.002 & 0.210 & 0.366 & 0.978 \\
\cline { 2 - 7 } & Peshawar & 0.336 & 0.002 & 0.231 & 0.408 & 0.981 \\
\hline \multirow{5}{*}{$\begin{array}{c}\text { Global Solar } \\
\text { Radiations }\end{array}$} & Karachi & 0.027 & 0.000 & 0.019 & 0.288 & 0.972 \\
\cline { 2 - 7 } & Hyderabad & 0.028 & 0.000 & 0.020 & 0.293 & 0.973 \\
\cline { 2 - 7 } & Lahore & 0.033 & 0.000 & 0.022 & 0.337 & 0.977 \\
\cline { 2 - 7 } & Quetta & 0.034 & 0.000 & 0.023 & 0.340 & 0.974 \\
\cline { 2 - 7 } & Peshawar & 0.037 & 0.000 & 0.025 & 0.379 & 0.976 \\
\hline
\end{tabular}

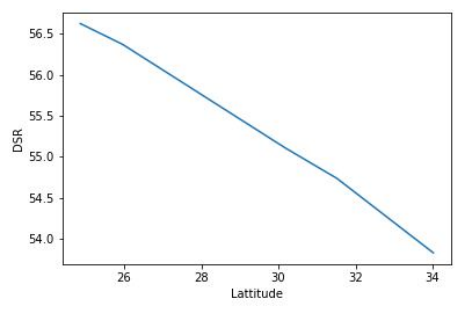

(a)

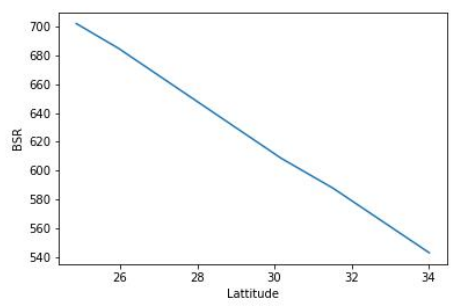

(b)

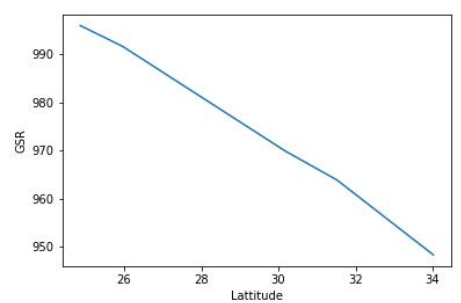

(c)

Figure 3The plot of (a) DSR, (b) BSR, and (c) GSR against Latitude 
Like BSR, DSR also hasa quadratic dependence on day-number (see equation (2)). The coefficients $b_{o}, b_{1}, b_{2}$ For five cities mentioned above are calculated by fitting calculated values of DSR using the ASHRAE model. Equations (12-16) relate BSR and day-number for Karachi, Hyderabad, Lahore, Quetta, and Peshawar, respectively. Like $a_{o}$, coefficient $b_{o}$ Have the same behavior, and it has maximum value for Karachi, which is depicted in fig. $1 \mathrm{~b}$. the top curve is for Karachi showing the highest values of DSR as compared to other cities. Like BSR, DSR is the least for Peshawar. The arrangement of five cities according to DSR flux is following, Karachi, Hyderabad, Quetta, Lahore, and Peshawar; it seems the order depends on their Latitude values (24.86, 25.96, 30.18, 31.52, 34.015), respectively, which have the same order as given above for DSR and BSR. Like BSR, the maximum value of DSR is almost the same for all cities, and it occurs in the middle of the year (182-184 days of the year).

Global solar radiation is also a function of daynumber (see equation (3)). Unlike BSR and DSR, GSR is not quadratic in day-number. Instead, it is a quintic function of 'n.' The coefficients are found by fitting and regression analysis. The corresponding values of coefficients for five cities are given in equations (17-21). The first coefficient $a_{o}$, like first coefficients $\left(a_{o}\right.$, and $\left.b_{o}\right)$ of DSR and BSR, plays the same rule in ordering the cities according to GSR flux. The trend continues, Karachi had the highest rank, and Peshawar had the lowest (see fig. 2c).

It has been that solar radiation values at a place are inversely related tothe latitudinal position of the region; for example, among five cities under study, Karachi has the lowest value of Latitude but overall values of GSR, BSR, and DSR are higher for the city (see Figure 2). Figure 3a-3c showsa plot of BSR, GSR, and DSR against latitudinal values of five cities. It is evident from the figure that all three radiations have inverse dependence of Latitude.

To check the validity of the fitting results, following four statistical errors Root Mean Square Error (RMSE), Mean Absolute Error (MABE), Mean Absolute Percent Error (MAPE), Chi-square Statistic $\left(\chi^{2}\right)$ and coefficient of determinations $\left(\mathrm{R}^{2}\right)$ is calculated. These errors are given in Table I.

$$
\begin{aligned}
& R M S E=\sqrt{\frac{\sum_{1}^{n}\left(\boldsymbol{R}_{s, i}-\boldsymbol{R}_{c, i}\right)^{2}}{n}} \#(22) \\
& M A B E=\frac{\sum_{i=1}^{n}\left|\boldsymbol{R}_{s, i}-\boldsymbol{R}_{c, i}\right|}{n} \#(23)
\end{aligned}
$$

$$
\begin{gathered}
\text { MAPE }=\frac{1}{n} \sum_{1}^{n}\left|\frac{R_{c, i}-R_{s, i}}{R_{c, i}}\right| \#(24) \\
\chi^{2}=\frac{1}{n} \sum_{1}^{n} \frac{\left(\left|R_{s, i}-R_{c, i}\right|\right)^{2}}{R_{c, i}} \#(25)
\end{gathered}
$$

Here $R_{s, i}$ are the standard values of radiations and $R_{c, i}$ is the calculated values by the mathematical models. In table 1, column 1 gives the type of radiations, and columns 2 shows cities, columns 4-8 give RMSE, $\chi^{2}$ MABE, MAPE, and $R^{2}$, respectively. $\chi^{2}$ values show that the fitting of three types of radiations is the best, coefficient determination values are reasonable, MAPE values are encouraging. The values of RMSE and MABE are less than one for global and diffused solar radiations, but for direct beam solar radiations, both RMSE and MABE are greater than one; nevertheless, the values are less than an accepted range of $10 \%$.

\section{CONCLUSION}

In this work, we studied solar radiation distribution for five cities (Karachi, Hyderabad, Quetta, Lahore, and Peshawar) of Pakistan. The direct beam, diffused, and global solar radiations for a year (365 days) at noon were calculated using the ASHARE clear sky model. Then by fitting and regression analysis, we developed mathematical equations for BSR, DSR, and GSR for five cities. Three equations for each city and altogether a total of 15 equations are developed for solar radiation calculations. The constant $a_{o}, b_{o}$, and $c_{o}$, play important rule, as they somewhat measure BSR, DSR, and GSR, respectively. Fig.2(a-c) gives variations of all three radiations as a function of day-number for the whole year. Karachi is the city receiving more solar radiation than any other city understudy, and Peshawar receives the lowest quantity of solar radiation. The critical aspect to be noted is that the maximum solar radiation occurs in the middle of the year (182-184 days), and the magnitude of solar radiation is almost the same for five cities. The ranks of the cities according to the receiving quantity of solar radiation is Karachi, Hyderabad, Quetta, Lahore, and Peshawar, and it links with the Latitude of these cities, which have the reverse order.

\section{REFERENCES}

1. Mote, M.P. and P. Zope, Volume 1, No. 2, May-June 2012 International Journal of Advanced Trends in Computer Science and Engineering Available Online at www. 
warse. org/ijatcse/info. html. International Journal, 2012. 1(2).

2. Abouhashish, M. Applicability of ASHRAE clear-sky model based on solar-radiation measurements in Saudi Arabia. in AIP Conference Proceedings. 2017. AIP Publishing LLC.

3. Gopinathan, K., Solar sky radiation estimation techniques. Solar Energy, 1992. 49(1): p. 9-11.

4. Ukhurebor, K. and I. Abiodun, Variation in annual rainfall data of forty years (19782017) for South-South, Nigeria. Journal of Applied Sciences and Environmental Management, 2018. 22(4): p. 511-518.

5. Poudyal, K.N., et al., Estimation of global solar radiation using clearness index and cloud transmittance factor at transHimalayan region in Nepal. 2012.

6. Prieto, J., J. Martínez-García, and D. Garcia, Correlation between global solar irradiation and air temperature in Asturias, Spain. Solar Energy, 2009. 83(7): p. 10761085.

7. Khatib, T. and W. Elmenreich, A model for hourly solar radiation data generation from daily solar radiation data using a generalized regression artificial neural network. International Journal of Photoenergy, 2015. 2015.

8. Adhikari, S. and E.R. Ivins, Climate-driven polar motion: 2003-2015. Science advances, 2016. 2(4): p. e1501693.

9. Linacre, E. and B. Geerts, Estimating the annual mean screen temperature empirically. Theoretical and applied climatology, 2002. 71(1): p. 43-61.

10. Rebetez, M., Changes in daily and nightly day-to-day temperature variability during the twentieth century for two stations in Switzerland. Theoretical and Applied Climatology, 2001. 69(1): p. 13-21.

11. Lawrence, M.G., The relationship between relative humidity and the dewpoint temperature in moist air: A simple conversion and applications. Bulletin of the American Meteorological Society, 2005. 86(2): p. 225-234.

12. Chabane, F., et al., Prediction of the global solar radiation on inclined area.Applied Solar Energy, 2019. 55(1): p. 41-47.

13. Eludoyin, O.M., et al., Air temperature, relative humidity, climate regionalization and thermal comfort of Nigeria. International Journal of Climatology, 2014. 34(6): p. 2000-2018.

14. Chandrasekaran, J. and S. Kumar, Hourly diffuse fraction correlation at a tropical location. Solar Energy, 1994. 53(6): p. 505510.

15. Górnicki, K., et al., Evaluation of models for the dew point temperature determination. Technical Sciences/University of Warmia and Mazury in Olsztyn, 2017: p. 241--257.

16. Frimpong, K., J. Oosthuizen, and E.J. Van Etten, Recent trends in temperature and relative humidity in Bawku East, Northern Ghana. 2014.

17. Adhikari, K.R., B.K. Bhattarai, and S. Gurung, Estimation of global solar radiation for four selected sites in Nepal using sunshine hours, temperature and relative humidity.Journal of Power and Energy Engineering, 2013. 1(03): p. 1.

18. Jamil, B. and M.M. Khan, Estimation of clear-sky solar radiation using ASHRAE model for Aligarh, India. International Journal of Engineering Research and Technology, 2014: p. 227-236. 


\section{Appendix A}

Values of AHRAE Constant on $21^{\text {st }}$ day of each month

ASHRAE constants A,B, and $\mathrm{C}$ on the twentyfirst day for each month

\begin{tabular}{|c|c|c|c|c|}
\hline Months & $\begin{array}{l}\text { No. } \\
\text { of } \\
\text { day } \\
\text { of } \\
\text { year }\end{array}$ & $\begin{array}{c}\mathrm{A} \\
(\mathrm{W} / \mathrm{m} 2) \\
\end{array}$ & B & $\mathrm{C}$ \\
\hline January & 21 & 1229.48 & 0.142 & 0.058 \\
\hline February & 52 & 1213.71 & 0.144 & 0.06 \\
\hline March & 80 & 1185.34 & 0.156 & 0.071 \\
\hline April & 111 & 1134.9 & 0.18 & 0.097 \\
\hline May & 141 & 1103.38 & 0.196 & 0.121 \\
\hline June & 172 & 1087.61 & 0.205 & 0.134 \\
\hline July & 202 & 1084.46 & 0.207 & 0.136 \\
\hline August & 233 & 1106.53 & 0.201 & 0.122 \\
\hline September & 264 & 1150.66 & 0.177 & 0.092 \\
\hline October & 294 & 1191.65 & 0.16 & 0.073 \\
\hline November & 325 & 1220.02 & 0.149 & 0.063 \\
\hline December & 355 & 1232.63 & 0.142 & 0.057 \\
\hline
\end{tabular}

